\title{
Calcium and Vitamin D Involvement in the Fragility Fracture of the Pelvis
}

\author{
ALEXANDRU FILIP1, OVIDIU ALEXA*, PAUL DAN SIRBU1*, CRISTIANA FILIP2*, ELENA COJ OCARU³, GABRIELA PUHA ${ }^{4}$, \\ MIOARA FLORENTINA TRANDAFIRESCU5 ${ }^{5}$, OANA VIOLA BADULESCU ${ }^{6}$ \\ ${ }^{1}$ Grigore T. Popa University of Medicine and Pharmacy, Faculty of Medicine, Department of Orthopedics and Traumatology \\ Surgical Sciences (II), 16 Universitatii Str., 700115, Iasi, Romania \\ ${ }^{2}$ Grigore T. Popa University of Medicine and Pharmacy, Faculty Of Medicine, Department of Biochemistry, Morpho-functional \\ Sciences (II), 16 Universitatii Str., 700115, Iasi, Romania \\ ${ }^{3}$ Grigore T. Popa University of Medicine and Pharmacy, Faculty of Medicine, Department of Morphopatology, Morfo-Functional \\ Sciences (I) 16 Universitatii Str., 700115, Iasi, Romania \\ ${ }^{4}$ Grigore T. Popa University of Medicine and Pharmacy, Faculty Of Medicine, Department of Internal Medicine, 16 Universitatii \\ Str., 700115, Iasi, Romania \\ ${ }^{5}$ Grigore T. Popa University of Medicine and Pharmacy, Faculty of Medicine, Department of Histology, Morfo-Functional Sciences \\ (I) 16 Universitatii Str., 700115, Iasi, Romania \\ ${ }^{6}$ Grigore T. Popa University of Medicine and Pharmacy, Faculty of Medicine, Department of Pathophysiology, Morfo-Functional \\ Sciences (II), 16 Universitatii Str., 700115, Iasi, Romania
}

\begin{abstract}
The fragility fracture is the widest spread of the bone diseases, in elderly. It particularly affects the vertebrae, the femur, the proximal humerus, the distal radius, the pelvis, thus preventing the patient's free movement. The most debilitating of all these fractures is the fragility fracture of the pelvis. This type of fracture raises supplementary problems compared to the other fractures due to the difficulties of diagnosis, surgical approach and to the longer recovery period. Choosing the right treatment for FFP is difficult due to health and comorbidities in elderly patients. Both conservative and surgical therapy involve equally large risks: prolonged immobilization or surgical risks. Therefore, pharmacological therapy is an alternative to surgery. Bisphosphonates prove their utility in the fracture-healing outcome, but the influence of calcium and vitamin $D$ were overlooked. The aim of our study was to evaluate the role of calcium and vitamin D in the healing process of patients with pelvic fragility fracture in osteoporotic patients with and without calcium and vitamin D supplementation. Our study shows that calcium and vitamin D exert a positive influence on the healing process of the fragility fractures and strongly emphasizes the need to educate patients to comply with the prescription to supplement calcium and vitamin D in order to improve fracture healing and prevent additional fractures.
\end{abstract}

Keywords: osteoporosis, fragility fracture, pelvis, calcium, vitamin D

Nowadays osteoporosis is one of the most common bone diseases encountered in older population. The major consequence of osteoporosis is the risk of fractures called fragility fractures (FF). Fragility fractures are serious medical problems, both due to the high costs of treatment and the severe decrease in the patient's quality of life. Fragility fracture occurs when structural changes suffered by the bone affect its biomechanical characteristics such as resistance to compression and torsional forces. The World Health Organization (WHO) defines a fragility fracture as one caused by a trauma that would be insufficient to injure bone if the bone substance were normal [1]. The most common fragility fractures are located in the vertebrae, femur, proximal humerus, distal radius. A particular case is the fragility fracture of the pelvis (FFP) whose incidence has increased lately. This type of fracture raises supplementary problems compared to the other fractures due to the difficulties of diagnosis, surgical approach and to the longer recovery period. As a general rule, literature recommends conservative treatmentas long as it leads to pain relief, allows mobilization and no displacements is noticed. Surgery is recommended when pain prevent patient to mobilize or when fractures are unstable [2, 3]. Alternatively, to surgery, pharmacological therapy can reduce the risk of fracture by $30 \%$ to $40 \%$ by using vitamin D, Ca supplementation, anti-osteoporotic (bisphosphonates, denosumab, raloxifene) or anabolic drugs (teriparatide) for bone repair [4]. The healing process of a fracture involves the participation of endogenous factors as well as exogenous factors such as vitamin D and calcium. Osteoporosis is characterized by increased calcium level but it is generated by the process of the systemic bone loss. More than $50 \%$ of the hypercalcemia cases, found in women, are associated with osteoporosis. In osteoporosis, detected calcium levels were greater than $2.56 \mathrm{mmol} / \mathrm{L}$, the reference range being $2.15-2.55 \mathrm{mmol} / \mathrm{L}$ [5] In the case of osteoporotic bone, the healing process is much slower [6] and the calcium and vitamin D deficiency has more severe consequences on systemic bone mineralization. The risk is even higher in the case of fractured osteoporotic bone when the increased calcium requirement for fracture-callus mineralization is provided by systemic bone resorption. In other words, post-traumatic bone loss leads to exacerbation of osteoporosis, increasing the risk of secondary fracture, 3 times [7]. The literature indicates that the subsequent bone loss after a fracture is estimated between 2-15\% of the bone mass [ 8-12]. Therefore, the need for the use of bone anti-resorption agents associated with calcium and vitamin D supplementation appears obvious [7]. The aim of our study was to evaluate the role of calcium and vitamin $D$ in the healing process of patients with pelvic fragility fracture in osteoporotic patients with and without calcium and vitamin D supplementation. Serum calcium and vitamin D levels 
were monitored during hospitalizations, 14 days and one month after discharge. The obtained data were correlated with the level of pain, its decrease being considered a sign of healing. The data obtained show that the healing process of the osteoporotic bone is improved when combining antiosteoporotic medication with calcium and vitamin D supplementation. This study indicates the need to educate patients in order to comply with the prescription of treatment and to supplement calcium and vitamin $D$ in order to improve fracture healing and prevent secondary fractures.

\section{Experimental part}

The study was realized on patients who experienced pelvic fracture, admitted between January 2015 and January 2019 at the St. Spiridon Emergency Hospital, Iasi, Romania. The inclusion criteria for the patients in the study were: osteoporotic patients aged 60 years and older. Exclusions criteria were: patients with pelvis injuries from high energy trauma or oncological bone diseases, patients not diagnosed with osteoporosis before fracture and osteoporotic patients with previous fractures in history. The fractures had been confirmed by X-ray or computer tomography. Clinical parameters as age, sex, comorbidities (diabetes, heart failure, renal failure etc), bone mineral density (BMD), osteoporosis therapy, alcohol/nicotine abuse and menopausal hormone therapy were recorded. Informed consent from all patients included in this study was obtained. The current research has been conducted in accordance to the ethical principles set out by the Helsinki Declaration and by the Ethical Committee from our university. Patients were divided in 2 groups: Group Ipatients receiving osteoporotic treatment (bisphosphonates) before fracture and supplemented with calcium and vitamin D, Group II- patients receiving osteoporotic treatment (bisphosphonates) before fracture but not supplemented with calcium and vitamin D by voluntarily not complying with the prescription or ceasing osteoporotic therapy, due to negligence, or other reasons. Group I contains 22 patients aged 63-85 years ( 16 women, 6 males). Group II contains 31 patients aged between 6081 years ( 23 women, 8 males). Patients in both groups was conservatively treated and received pain medication. Patients were monitored for a short-term follow-up during hospitalization, in our clinic or in specialized recovery department, for 14 days and 1 month after hospital discharge. During hospitalization we monitored the time required to reduce pain by using the visual analog scale or VAS [4]. Relieving pain was considered a favorable sign in the healing process. Patients with constant or increased pain were re-evaluated by X-ray to identify fracture displacement or other causes and were excluded from the study. At admission, routine analyses including serum calcium levels were determined for all patients in hospital laboratory. Vitamin D was also determined for patients in the biochemistry department by using a $25-\mathrm{OH}$ vitamin $\mathrm{D}$
DRG Elisa kit 5396 for manual use. The one-month followup was done either by patient re-assessment or by interviewing patients by telephone. At one month after discharge, $15(67 \%)$ patients from group I and $19(61 \%)$ from group II, came back for re-assessment. They were investigated for X-ray radiography, serum calcium and vitamin $\mathrm{D}$ levels.

\section{Results and discussions}

Fractures are widely encountered in osteoporotic patients. In group I, the appearance of FFP, in patients undergoing osteoporotic therapy and calcium and vitamin D supplementation, may be caused by an older age in this group. The administration of bisphosphonates is effective in preventing fractures in $40 \%$ of osteoporotic patients over 70 years (reported data for the femur), but does not show similar improvements over 80 years of age $[13,14]$. In group II, the fracture is caused by non-complying to the therapy; the literature indicates an FF incidence of 30\% $50 \%$ (including hip, shoulder, humerus, pelvis) in patients who do not follow the treatment as prescribed [15]. In the case of any fracture including FFP, pain reduction is an indication of the favorable evolution of the healing process. Pain can be assessed with a VAS score whose interpretation after ensen [16] is realized on a scale of $10 \mathrm{~cm}(100 \mathrm{~mm})$ as follows: no pain (0-4 mm), mild pain (5-44 mm), moderate pain (45-74 $\mathrm{mm}$ ) and severe pain $(75-100 \mathrm{~mm})$. The influence of calcium in the healing process of the osteoporotic fracture is assessed by correlating its serum profile with pain reduction, is shown in figures 1 (a) and respectively figure 1 (b).

For group I-in osteoporotic patients previously supplied with calcium and vitamin $\mathrm{D}$, the pain decreases and reach the mild range around the $8^{\text {th }}$ day after admission. For group II -in osteoporotic patients not supplied previously with calcium and vitamin $D$, the pain decreases and reach the mild range around the $10^{\text {th }}$ day. Serum calcium levels decrease after fracture, in both groups. The decrease is moderate in group I, severe in group II, and statistically significant between the two groups $(p<0.005)$. This behavior was noticed as an effect to the initiation of the remodeling process [8]. Calcium is essential for the callus mineralization. The calcium needed for this process is obtained on account of systemic bone resorption in favor of fracture healing. Therefore, the loss of systemic bone mass in the case of osteoporosis is much accentuated in the context of a calcium deficiency. As shown in Figure 1 (b), the low levels of calcium coincide with a delay of the pain reduction time which, although insignificant, indicates a longer time span for the fracture healing. Therefore, calcium supplementation in FFP becomes necessary not only to support the fracture healing but also to avoid additional fractures. Vitamin D levels were determined at admission to the hospital for all patients in groups I and II and one month after discharge only for patients who presented for reassessment. The optimal level of vitamin

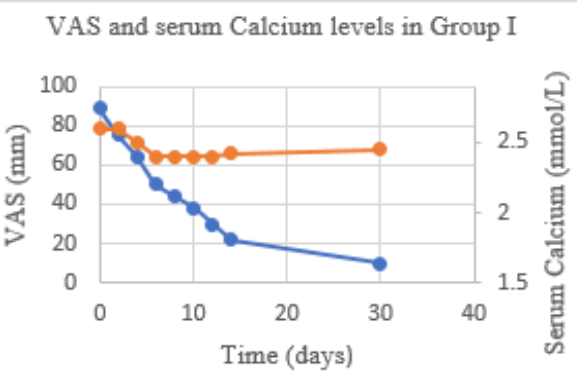

1(a)

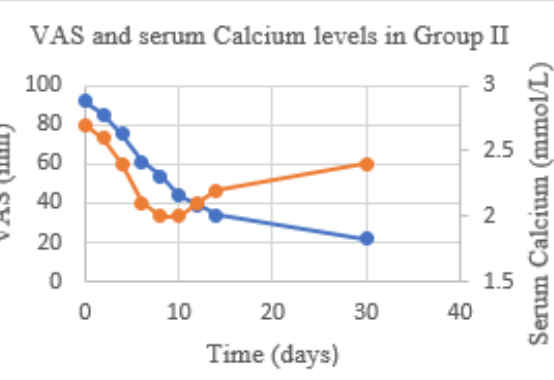

1(b)
Fig. 1. The serum calcium profile during the short-follow up 
D indicated by the literature is between $25-80 \mathrm{ng} / \mathrm{mL}$, with vitamin insufficiency below $30 \mathrm{ng} / \mathrm{mL}$ and vitamin deficiency below $20 \mathrm{ng} / \mathrm{mL}$ [17]. The blood concentrations of vitamin $D$ at the time of the fracture were at the lower limit for patients in group I ( $25 \mathrm{ng} / \mathrm{mL} \pm 3.52)$ and well below this value (17 $\mathrm{ng} / \mathrm{mL} \pm 2.28)$ for those in group II, the difference between the two groups being statistically significant $(p<0.001)$. The values recorded in this study indicate vitamin insufficiency in group I, and vitamin deficiency, in group II, both situations favoring fracture production. One month after discharge the follow-up on patients who returned to control show that during the recovery, they resumed the treatment with bisphosphonates and supplemented calcium and vitamin D. Thus, vitamin D levels, one month after discharge, are in the reference range, for both groups as follows: $37 \pm 3.57$ $\mathrm{ng} / \mathrm{mL}$ for group I respectively $33 \pm 3.89 \mathrm{ng} / \mathrm{mL}$ for group II. Although both groups present normal vitamin D levels, these concentrations are near the lower limit range. That indicates that the recovery evolved differently, being slower for the group II. Different authors suggest different vitamin D levels for optimal bone metabolism: greater than 30ng/ $\mathrm{ml}$ [18] or better between $40-60 \mathrm{ng} / \mathrm{mL}$ [19]. Patients returned to reassessment were investigated for X-ray radiography which highlighted the callus formation. The dimensions and density of the callus were different in the two groups, which confirms their different recovery. Thus, group I presented fully formed callus and group II presented reduced callus in volume and density. Vitamin D is essential in callus mineralization [20] and probably intervenes also in its formation, therefore, a vitamin deficiency may slow down bone recovery. On the other hand, it is known that although the bisphosphonates delay the remodeling of the callus, they increase the volume by blocking the bone turnover [21,22]. Thus, the increased volume of the callus in group I may be the result of bisphosphonate therapy while the characteristics of the callus in group II may be an indication of a deficientbone remodeling in which recovery was performed in the context of the previous vitamin D deficiency. The obtained data indicate that osteoporotic patients with calcium and vitamin D supplementation show a better recovery. The recommended amounts of calcium and vitamin D for osteoporotic patients over 50 years of age are $1200 \mathrm{mg}$ [ 23] respectively $32 \mathrm{ng} / \mathrm{mL}$ ( 75 $\mathrm{nmol} / \mathrm{L}$ ) [24]. In osteoporotic patients, post-fracture vitamin D administration is recommended for 5 to 8 weeks with calcium levels checking [25]. Supplementation of osteoporotic treatment with calcium and vitamin D should become mandatory especially for osteoporotic patients who have suffered a fracture, as they have a 2 to 4 -fold increased risk of future fracture [8].

\section{Conclusions}

Calcium and vitamin D exert a positive influence on the fracture-healing outcome. They are the main nutrients in normal as well as osteoporotic bone remodeling. In the case of any fracture (including FFP) for the surgeon, the stabilization and reduction of the fracture are the main priorities. This may lead to overlook of the administration/ supplementation with calcium and vitamin D which may prevent systemic bone loss and reduce the risk of secondary fractures.

The present study revealed the therapeutic potential of calcium and vitamin D supplementation after the fragility fracture in patients with insufficient calcium and vitamin D status.

\section{References}

1.OBERKIRCHER, L., RUCHHOLTZ, S., ROMMENS, PA, HOFMANN, A., BUCKING, B., KRUGER, A., Osteoporotic pelvic fracture, Deutsches Ärzteblatt International, 115, nr. 5, 2018, p. 70

2.ROMMENS, P.M., WAGNER, D., HOFMANN, A., Fragility fractures of the pelvis,J. Bone Jt. Surg. Rev., 5, 2017, p.1

3.KRAPPINGER, D., KAMMERLANDER, C., HAK, D.J ., BLAUTH, M., Low-energy osteoporotic pelvic fractures, Arch. Orthop. Trauma. Surg., 130, 2010, p. 1167

4.FILIP, A., VELICEASA, B., PUHA, B., FILIP, C., POPESCU, D., ALEXA, O., Bisphosphonates Influence and Pain Assessment in Mobilization of Patients with Fragility Fracture of the Pelvis, Rev. Chim. (Bucharest), 70, no. 3, 2019, p. 1094

5.DALEMO, S., EGGERTSEN, R., HJERPE, P., ALMQVIST, E.G., BENGTSSON BOSTROM, K., Bone mineral density in primary care patients related study to serum calcium concentration: a lomgitudinal cohort study from Sweden, Scand J Prim Health Care, 36, nr.2, 2018, p.198.

6.KNUT,STROMSOE.Fracture fixation problems in osteoporosis. Injury, Int J Care Injured. 35, 2004; p. 107. 7.FISCHER, V., HAFFNER-LUNTZER, M., AMLING, M., IGNATIUS, A., Calcium and vitamin $D$ in bone fracture healing and post-traumatic bone turnover, European Cells and Materials, 35, 2018, p. 365 8.AHMED, L.A., CENTER, J.R., BJ ORNEREM, A., BLUIC, D., J OAKIMSEN, R.M., JORGENSEN, L., MEYER, H.E., NGUYEN, N.D., NGUYEN, T.V., OMSLAND, T.K., STORMER, J., TELL, G.S., VAN GEEL, T.A., EISMAN, J.A., EMAUS, N., Progressively increasing fracture risk with advancing age after initial incident fragility fracture: the Tromso study., J Bone Miner Res., 28, 2013, p. 2214

9.GHEORGHEVICI, T.S., PUHA, B., ALEXA, O., Open radiocarpal dorsal fracture-dislocation associated with chronic distal radioulnar joint dislocation: a case report, Rev Med Chir Soc Med Nat lasi, 121, nr. 1, 2017, p. 143.

10.GHEORGHEVICI,T.S.,VELICEASA, B., PUHA, B.,TOADER,S., ALEXA,I.,D., ALEXA,O., Preoperative Hemoglobin Dynamics in Patients with Trochanteric Fractures A multivariate analysis, Rev. Chim.(Bucharest), 69, no.11, 2018, p. 4220.

11.MALANCEA, R.,GAVRILIUC, E.,R., VELICEASA,B., PUHA,B., POPESCU,D., ALEXA,O., Methodology of Three-dimensional Printing in Acetabular Fractures, Mat. Plast.,54, no.3, 2017,p.513.

12.BADULESCU, O. V., CIOCOIU, M., FILIP, N., VERINGA, V., The Efficiency of Substitutive Treatment with Moroctocog Alfa in Managing Hemostasis in Patients with Hemophilia A Without Inhibitors With Total Knee Arthroplasties, Rev. Chim. (Bucharest), 69, no.12, 2018, p.3702.

13.TSUDA, T., Epidimiology of fragility fracture and fall prevention in the elderly: a systematic review of literature, Curr Orthop Pract., 28, no. 6,2017, p. 580

14.GREENSPAN, S.L., PERERA, S., FERCHAK, M.A., et al., Efficacy and safety of single-dose zoledronic acid for osteoporosis in frail elderly women: a randomized clinical trial. JAMA Intern Med., 175, 2015, p.913 15.MEARS, S.C., KATES, S.L., A guide to improving the care of patients with fragility fractures, Edition 2., Geriatr Orthop Surg Rehabil., 6, nr. 2, 2015, p.58

16.J ENSEN, M.P., CHEN, C., BRUGGER, A.M., J . Interpretation of visual analog scale ratings and change scores: a reanalysis of two clinical trials of postoperative pain, Pain, 4, nr. 7, 2003, p. 407.

17.KENNEL, K.A., DRAKE, M.T., HURLEY D.L., Vitamin D deficiency in adults: when to test and how to treat, Mayo Clin. Proc., 85, nr.8, 2010, p.752.

18.VON DOMARUS, C., BROWN, J., BARVENCIK, F., AMLING, M., POGODA, P., How much vitamin D do we need for skeletal health?, Clin Orthop Relat Res, 469, 2011, p.3127.

19.*** https://ww w. health.harvard.edu/blog/vitamin-d-whats-rightlevel-2016121910893

20.GORTER, E.A., KRIJ NEN, P., SCHIPPER, I.B., Vitamin D status and adult fracture healing, J Clin Orthop Trauma., 8, nr.1, 2017, p.34 
21.HEGDE, V., JO, J.E., ANDREOPOULOU, P., LANE, J.M., Effect of osteoporosis medication on fracture healing, Osteoporos Int, 27, nr.3, 2016, p.861.

22.SHIN, Y.S., JUNG, H.J., SAVALE, A.P., HAN, S.B., Unusual Excessive Callus Formation in the Intertrochanteric Fracture Treated with Teriparatide., Hip\&Pelvis, 26, nr. 1, 2014,p,41.

23.ROSS, A.C., TAYLOR, C.L., YAKTINE, A.L., DELVALLE, H.B., Dietary Reference Intakes for Calcium and Vitamin D, Washington D.C: The national academies press, 2011.
24.NEUPANE, S., KNOHL, S.J., The Institute of Medicine, the Food and Drug Administration, and the calcium conundrum. Public Health Nutr.,17, nr. 8, 2014, p.1865.

25.BISCHOFF-FERRARI, H.A., Optimal serum 25-hydroxyvitamin D levels for multiple health outcomes., Adv Exp Med Biol.,810, 2014; p.500.

Manuscript received: 26.09 .2019 